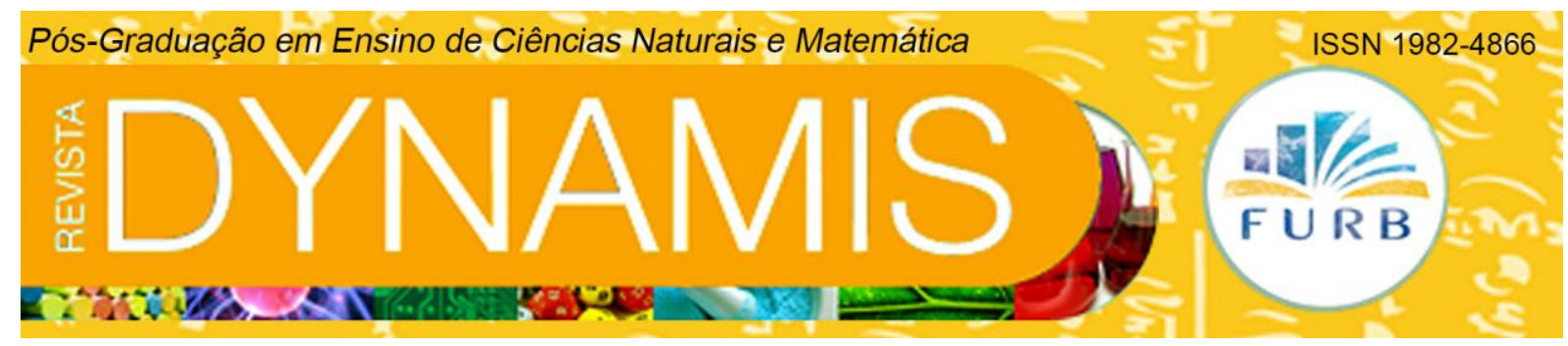

\title{
GUIA DO EDUCADOR PARA O FILME OSMOSE JONES
}

\author{
Educator's guide to the Osmose Jones Film
}

\section{Monica Santos Cruz}

Especialista em Ensino de Ciências e Biologia pela Pontifícia Universidade Católica de Minas Gerais Mestranda em Ensino de Ciências, programa ProMestre, pela Faculdade de Educação da Universidade Federal de Minas Gerais

Professora de Biologia da Rede Estadual de Minas Gerais

Professora de Ciências da Rede Municipal de Belo Horizonte

monicasancruz@yahoo.com.br

\section{Marcelo Diniz Monteiro de Barros}

Doutor em Ensino em Biociências e Saúde pelo Instituto Oswaldo Cruz - Fiocruz

Professor Adjunto IV do Departamento de Ciências Biológicas da Pontifícia Universidade Católica de Minas Gerais

Professor Colaborador do Programa de Pós Graduação em Ensino em Biociências e Saúde pelo Instituto Oswaldo Cruz - Fiocruz

Professor Nível IV, Grau A, da Faculdade de Educação da Universidade do Estado de Minas Gerais marcelodiniz@pucminas.br 


\title{
Resumo
}

O tema "Ser humano e saúde" é um dos eixos centrais para a educação em ciências no ensino fundamental, determinado nos PCNs (1998). Contudo, no ensino deste tema, o professor encontra algumas dificuldades, começando pelos conceitos científicos, alguns de difícil assimilação por parte dos alunos, uma vez que não são fenômenos observáveis e os alunos apesar de estarem iniciando uma fase de maior desenvolvimento cognitivo, ainda apresentam dificuldade na capacidade de fazer abstrações. A proposta deste artigo é oferecer aos professores um recurso pedagógico, chamado Guia do Educador para o filme Osmose Jones uma aventura radical pelo corpo humano, o qual foi criado pensando-se nas dificuldades encontradas pelos professores na atualidade, nas especificidades definidas nos PCNs de Ciências para o ensino do Corpo Humano e na necessidade de novos materiais didáticos. Assim, no guia foram discriminadas atividades que o professor pode dispor em suas aulas diárias, como recursos complementares, tornando mais atraente o ensino e facilitando o estudo e o conhecimento do corpo humano.

Palavras Chaves: Ensino de Ciências. Guia do Educador. Filme Osmose Jones. Corpo Humano.

\begin{abstract}
The theme "Human and health" is one of the central axes for an-elementary science education, determined in the PCNs (1998). However, in teaching this subject, the teacher encounters some difficulties, beginning with the scientific concepts, some of the difficult assimilation by the students, since they are not observable phenomena and the students despite are starting a phase of more cognitive development still presented difficulty in making abstractions. The proposal of this article is offer teachers a pedagogical resource called Educator's Guide for the movie Osmosis Jones - a radical adventure for the human body, which was created considering the difficulties encountered by teachers in the present time, in the specificities defined in the PCNs of Sciences for the teaching of the Human Body and in the need of new didactic materials. Thus, the guide outlined the activities that the teacher can have in his daily classes as complementary resources, making teaching more attractive and facilitating the study and knowledge of the human body.
\end{abstract}

Keywords: Science Education, Educator's guide, film Osmosis Jones, Human Body. 


\section{INTRODUÇÃO}

O professor de Ciências geralmente apresenta uma grande dificuldade quando o precisa lidar com temas de ensino acerca de níveis microscópicos, o que pode muitas vezes colaborar para que os alunos percam o interesse nas atividades desenvolvidas, por não compreendê-las. Caballer e Giménez (1992) abordaram a dificuldade por parte dos alunos na mudança de concepções prévias relacionadas aos temas científicos. Dentro das perspectivas colocadas neste trabalho a primeira é justamente a de que "compreender que os seres vivos são formados por células não é algo fácil uma vez que não é um fenômeno diretamente observável de maneira cotidiana" (CABALLER; GIMÉNEZ, 1992, p. 178, tradução nossa).

Junto a isso se pode agregar o fato de que muitos professores encontram dificuldades em criar estratégias pedagógicas diferenciadas para estimular a participação de seus alunos, seja por características individuais próprias, que limitem esta criação; seja pela dificuldade em participar de cursos de formação nos quais é possível realizar trocas de experiências e atualizar-se em relação ao conteúdo e novidades na área de ensino; seja também pela dificuldade em lidar com uma geração que desde cedo está imersa no uso de novas tecnologias e que agora está ingressando no sistema educacional. Este que "ainda tenta transferir o conhecimento como se fazia há 100 anos. Isso não seria um problema, se toda a estrutura econômica de nossa sociedade ainda fosse a mesma, mas não é o caso". (VEEM; VRAKKING, 2009, p. 13)

Essa nova geração é chamada por Veem e Vrakking (2009, p. 12) de "Homo zappiens". É uma geração que:

[...] cresceu usando múltiplos recursos tecnológicos desde a infância [...] esses recursos permitiram às crianças de hoje ter controle sobre o fluxo de informações, lidar com informações descontinuadas e com sobrecarga de informações, mesclar comunidades virtuais e reais, comunicarem-se e colaborarem em rede, de acordo com suas necessidades.

O fato é que o uso de mediadores que promovam uma aprendizagem significativa ao despertar o interesse do (a) aluno (a), contribuindo também para que ele (ela) desenvolva sua autonomia de uma forma divertida pode ser uma opção para lidar com estas dificuldades. É importante lembrar que, o conceito de aprendizagem significativa está relacionado à capacidade do indivíduo de fazer a interação entre novas informações com estruturas de conhecimento específico que ele já possua (MOREIRA, 1999).

Contudo, nem toda escola tem a disposição recursos tecnológicos avançados, como programas e jogos de computador, para que professores e alunos façam uso. No entanto, é preciso ter em mente a definição de recurso didático dada por Souza $(2007$, p. 111) como "todo material utilizado como auxilio no ensino - aprendizagem do conteúdo proposto para ser aplicado pelo professor a seus alunos".

Nesta perspectiva é que se embasa o presente trabalho, que tem por justificativa tentar ajudar a sanar um pouco dos problemas aqui citados, oferecendo aos professores a proposta de um recurso didático, que consiste num produto final desenvolvido em uma disciplina de pósgraduação, que tinha como um de seus objetivos o preparo de seus participantes para a confecção de recursos pedagógicos diferenciados para o ensino de Ciências e/ou Biologia.

O resultado final consistiu na elaboração do recurso pedagógico intitulado: Guia do Educador para o filme "Osmose Jones - uma aventura radical pelo corpo humano". 
O guia traz propostas de atividades para complementação da prática pedagógica no desenvolvimento do eixo temático Ser Humano e Saúde, pertencente aos Parâmetros Curriculares Nacionais (BRASIL, 1998) de Ciências Naturais, no que diz respeito à compreensão do funcionamento integral dos sistemas que compõem o nosso corpo, bem como da importância e necessidade de cuidados que este corpo precisa para se manter saudável.

\title{
2 FUNDAMENTAÇÃO TEÓRICA
}

Ao se construir um recurso pedagógico, uma das questões em que o educador deve se basear é: Qual o objetivo do meu recurso?

Afinal a utilização de recursos didático-pedagógicos diferenciados é muito importante, principalmente quando estes podem "preencher as lacunas que o ensino tradicional geralmente deixa, e com isso, além de expor o conteúdo de uma forma diferenciada, fazer dos alunos participantes do processo de aprendizagem" (CASTOLDI; POLINARSKI, 2009, p. $685)$.

Contudo, o educador deve estar atento ao uso do recurso que irá fazer.

\begin{abstract}
Para que os recursos didáticos possam promover uma aprendizagem significativa, é necessário que o professor esteja preparado, capacitado, ter criatividade para explorar os recursos que estão ao seu alcance, com o objetivo de aproveitar todos os benefícios que os mesmos possam proporcionar. O professor deve se planejar para que a aplicação desses recursos não se torne meramente uma ação recreativa, eles devem ser usados dentro do processo de ensino-aprendizagem, contribuindo para assimilação do conteúdo ministrado na disciplina, por parte dos alunos. (SILVA et al, 2012, p. 3).
\end{abstract}

Atualmente estes recursos não precisam se limitar ao quadro e giz. O professor pode buscar fazer uso de recursos que ao envolver a ludicidade, possibilitem a ele tornar sua aula mais atrativa, o que pode levar a uma participação massiva dos estudantes. A sociedade atual vive uma era com diversos recursos tecnológicos avançados, os quais são muito atrativos, mas há de se considerar que nem todas as escolas, principalmente as públicas, podem dispor destes recursos. O que se propõe neste relato é mostrar a possibilidade do professor de fazer uso de filmes, especialmente aqueles que fazem parte do cotidiano dos alunos, e que abordam, das mais variadas formas, temas do ensino de ciências.

$\mathrm{Na}$ adolescência, é alcançada a independência do real, surgindo o período das operações formais. Seu caráter geral é o modo de raciocínio, que não se baseia apenas em objetos ou realidades observáveis, mas também em hipóteses, permitindo, dessa forma, a construção de reflexões e teorias. O pensamento torna-se então hipotético-dedutivo. (FERRACIOLI, 1999, p. 8).

Se for levada em consideração esta fase de desenvolvimento em que os alunos do ensino fundamental se encontram, e que muitos filmes conseguem de forma lúdica ajudá-los nesta construção de hipóteses, reflexões e teorias é possível para o professor, ao fazer uso de algum desses filmes, tornar sua aula mais atrativa, contribuindo para a formação do pensamento hipotético dedutivo de seus alunos. 


\title{
3 CONTEXTUALIZAÇÃO
}

O objetivo maior de se trabalhar o Eixo temático "Ser Humano e Saúde", conforme registrado nos PCNs (BRASIL, 1998), com os alunos que se encontram no $3^{\circ}$. Ciclo do Ensino Fundamental é fazer com que estes tenham a compreensão do corpo como um todo e da saúde humana, integrados pelas dimensões orgânica, ambiental, psíquica e sociocultural.

As noções básicas de funções e de cuidados são iniciadas nos anos anteriores, mas nesta fase da vida já é possível ao aluno fazer associações de caráter mais abstrato, podendo assim compreender a existência de estruturas microscópicas em nosso organismo estendendo suas reflexões para temas não palpáveis, como o entendimento das minúsculas estruturas que fazem parte do seu corpo.

O fato dos alunos estarem aumentando suas relações sociais, pois passam a descobrir um pouco mais do mundo, além do que é mostrado nos laços familiares, associado com as mudanças físicas, características da adolescência, traz a eles a possibilidade de contato com uma série de situações que estimulam ainda mais sua curiosidade.

Outra questão observada é o desenvolvimento de habilidades de cunho cognitivo:

\begin{abstract}
Os alunos do terceiro ciclo, comparados aos do ciclo anterior, geralmente ampliaram o domínio sobre a linguagem escrita e falada. Não se pode perder de vista que, ao chegar à quinta série, é comum que o aluno fale mais e melhor do que escreva e leia. No discurso oral está à expressão mais completa de suas hipóteses explicativas para suas observações acerca dos fenômenos naturais e demais objetos de conhecimento da área de Ciências. (BRASIL, 1998, p. 58).
\end{abstract}

Cabe ao professor estar atento a estas características de seus alunos, buscando desenvolver atividades que estimulem o aprendizado coletivo. Atividades lúdicas que trabalhem a oralidade, o trabalho coletivo e a reflexão são especialmente recomendados para esta fase:

O mais importante não será o recurso, mas sim, a discussão e resolução de uma situação problema ligada ao contexto do aluno, ou ainda, à discussão e utilização de um raciocínio mais abstrato, tendo como proposta formar um aluno reflexivo com relação ao seu contexto social e também voltado ao contexto mundial, que sofre transformações muito significativas a cada momento e esse aluno deve ter condições de acompanhar essas transformações. (SOUZA, 2007, p. 112).

\subsection{O EIXO TEMÁTICO SER HUMANO E SAÚDE NOS PCNS DE CIÊNCIAS NATURAIS}

Para este nível de ensino, a recomendação dada no estudo do eixo temático Ser Humano e Saúde inicialmente é que o aluno seja capaz de entender as características de seu corpo por meio da comparação destas com as de outros seres vivos.

Não cabe nesta fase que o aluno entenda mecanismos e estruturas celulares, mas sim que possa compreender como o seu organismo funciona de forma integrada, e que esta integração muitas vezes é dependente de fatores externos, como condições ambientais ou mesmo as condições socioeconômicas a que cada indivíduo está sujeito. 
Assim os temas transversais Saúde, Orientação Sexual, Meio Ambiente, Trabalho e Consumo, Ética e Diversidade Cultural são inseridos e trabalhados conjuntamente ao conteúdo básico da disciplina por meio de assuntos diversos.

Um exemplo é quando ao trabalhar Sistema Digestório, na abordagem de doenças relacionadas ao sistema, o professor explore a questão de que várias doenças atuais são resultado do estilo de vida a que as pessoas se sujeitam, como o caso da obesidade e da hipertensão arterial.

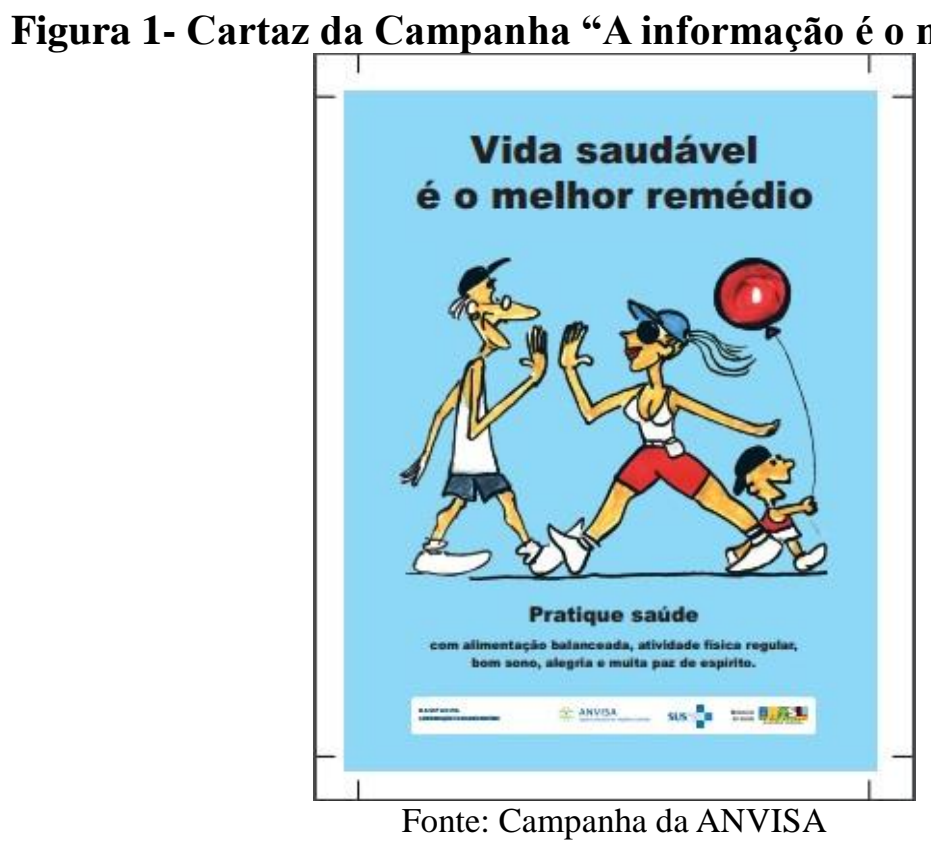

Outro exemplo envolve as diferenças socioeconômicas presentes no mundo. Observa-se que grande parte da população não tem acesso a saneamento básico, o que coloca as pessoas vulneráveis a uma série de doenças que em outras partes do mundo foram consideradas erradicadas, como o cólera e a disenteria.

A influência midiática negativa sobre a vida das pessoas é outra questão a ser levada em consideração, que vai desde a divulgação de produtos alimentícios industrializados, consumo em excesso de vitaminas, bebidas alcoólicas, cigarros, até a determinação de padrões estéticos.

Estes tipos de associações podem ser feitas nos estudos de todos os sistemas. O professor deve estar atento à realidade e necessidade dos alunos com os quais estará trabalhando, o que inclui considerar os aspectos emocionais destes e mostrar como isso também influencia o funcionamento do organismo:

É necessário estabelecer as relações dos vários sistemas entre si e com os processos mentais, as emoções, os pensamentos e as intuições, para que nosso corpo seja compreendido como unidade. Os aspectos emocionais estão geralmente ausentes, como se o corpo e a mente humanos fossem entidades diferentes e estanques. Mesmo em se tratando de alimentação ou de locomoção, o professor pode sublinhar a participação dos processos mentais no seu funcionamento, facilitando o entendimento do corpo como um todo (BRASIL, 1998, p. 76). 


\subsection{AUTOMEDICAÇÃO E ADOLESCÊNCIA}

Considerando o mundo atual em que as pessoas têm acesso muito rápido a qualquer informação, mas não orientação, e que em grande parte das famílias observa-se que os adolescentes passam a maior parte do tempo sem o acompanhamento de um adulto, proporcionar a discussão sobre um comportamento de risco, no caso a automedicação, é primordial.

Definida como a ação de medicar-se por conta própria $^{1}$, a automedicação é um ato muito comum nas famílias brasileiras, fortalecido pelas campanhas publicitárias e muitas vezes por atitudes pessoais de descaso com o organismo, como a "preguiça" de ir ao médico; ou pela dificuldade de ter acesso a um profissional de saúde, alegado por usuários do sistema único de saúde - SUS, como se verifica em uma pesquisa feita com estudantes de dez escolas no município de Fortaleza sobre automedicação:

Constatou-se que muitos adolescentes entendiam que se podem tomar medicamentos por conta própria, porém não justificaram tal asserção. Quanto aos riscos da automedicação, os estudantes relataram que sabiam ou sabiam parcialmente de tais riscos, mas grande parte não justificou a resposta. Esses dois fatos ressaltam a falta de informação e/ou orientação nesta temática, motivo relatado pelos estudantes como uma das razões para que as pessoas façam uso de medicamentos sem a prescrição médica. (SILVA et al, 2011, p. 1657-8).

\section{Figura 2 - Cartaz da Campanha "A informação é o melhor remédio".}

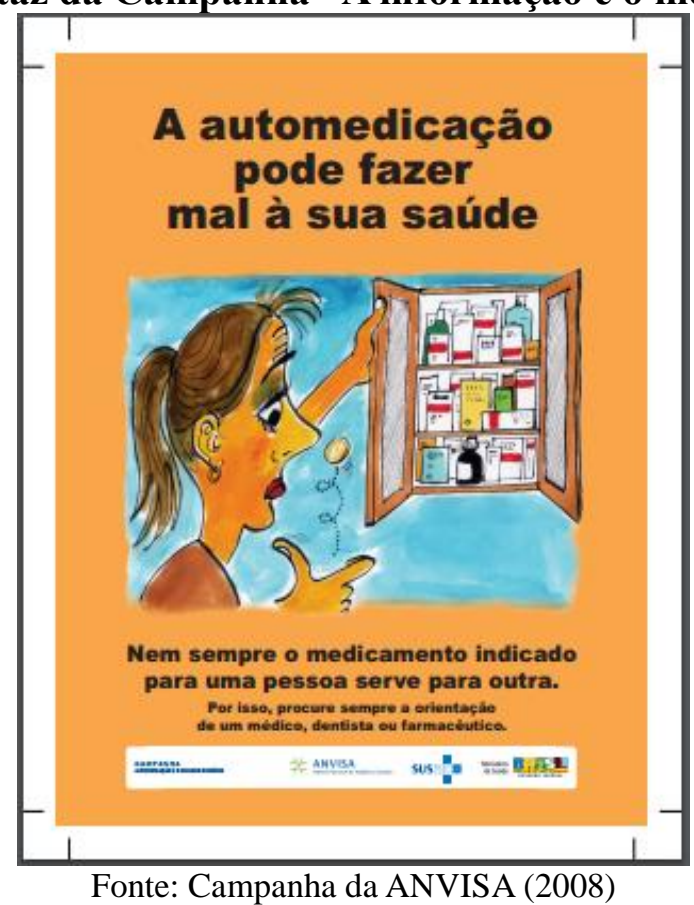

Definição presente em material de apoio da campanha "A Informação é o melhor remédio" desenvolvida pela Agência Nacional de Vigilância Sanitária - ANVISA em conjunto com o Departamento de Assistência Farmacêutica - DAF/MS, iniciada em 2006 com Kit de apoio lançado em 2008. Encontra-se disponível no site da Agência Nacional de Vigilância Sanitária (http://www.anvisa.gov.br) 
O fato é que o ato de tomar um medicamento só porque este foi prescrito para um conhecido e funcionou, ou mesmo porque a propaganda diz que ele combate determinados sintomas é uma ação muito perigosa que pode levar a efeitos colaterais, muitas vezes com danos permanentes.

Realizar discussões, em torno deste tema, com os alunos, pode se configurar como estratégia de prevenção contra tal atitude, até porque a escola acaba sendo a única fonte de informação para grande parte dos adolescentes.

\section{O GUIA DO EDUCADOR}

Procurando na literatura o significado específico de "Guia do Educador" não se encontra nenhum resultado específico. Considerando então, um dos significados para "Guia" dado como "ação de guiar"2 pode-se considerar que um Guia do Educador consiste numa série de atividades que poderão guiar professores e alunos para se alcançar um dado objetivo.

E esta foi à proposta dada aos alunos do curso de pós-graduação: que construíssem um Guia do Educador a partir do uso de algum tipo de recurso (música, poema, filme, etc) que pudesse ser usado como estratégia para o desenvolvimento de um dado conteúdo ou tema nas aulas de Ciências ou Biologia.

No caso deste relato o guia traz a utilização do filme "Osmose Jones - uma aventura radical pelo corpo humano", que assume a função de ferramenta motivadora na discussão de conteúdos de ciências.

Figura 3 - Capa brasileira do DVD do filme Osmose Jones e Dhrix

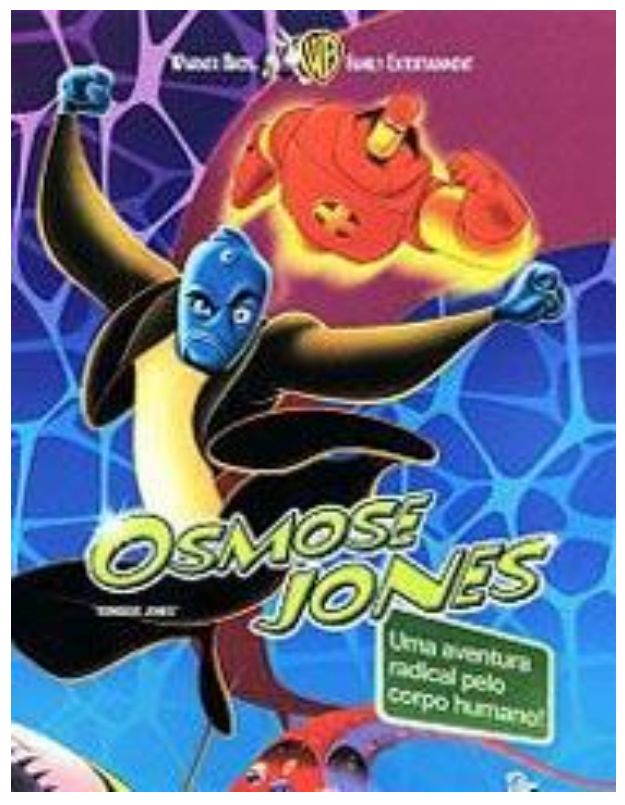

Fonte: Disponível em:

http://dublanet.com.br/forum1/attachment.php?attachmentid=3997\&d=1341700400\&thumb=1

\footnotetext{
${ }^{2}$ Significado presente no dicionário online de Português. Disponível em: https://www.dicio.com.br/guia/. Acesso em 23 jan. 2016.
} 
A escolha do filme se deu por alguns motivos, entre eles: a linguagem usada é acessível aos adolescentes; trata-se de uma mistura de liveaction $^{3}$ com animação, o que o torna atrativo para o público em questão; bem como o fato de ser uma comédia.

O filme é uma produção norte americana do roteirista Marc Hymande de 2001. Nele duas histórias paralelas são apresentadas: primeiro a vida de Frank, homem viúvo, funcionário de um zoológico e que não apresenta preocupações no que diz respeito aos seus hábitos alimentares, de higiene ou mesmo a prática de atividades físicas, totalmente o oposto de sua filha adolescente, Shane, que procura convencer o pai da necessidade de mudar seus hábitos, na busca por uma vida mais saudável.

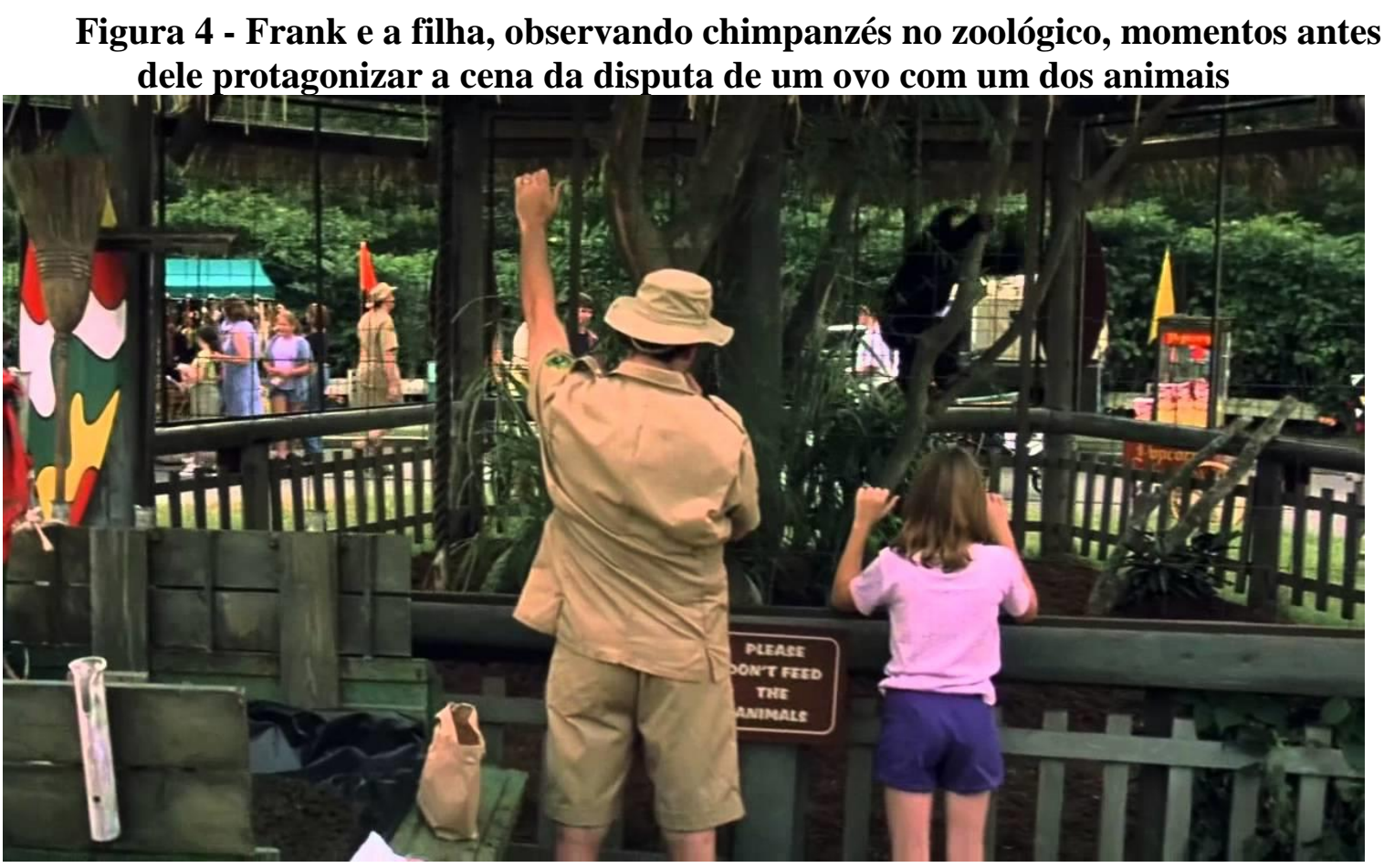

Fonte: Imagem disponível em https://i.ytimg.com/vi/ooIIw2iuRsk/maxresdefault.jpg

Uma das cenas que retrata os descuidos de Frank para com sua saúde é quando este, ao ser visitado pela filha, no trabalho, vai almoçar e acaba disputando um ovo com um chimpanzé. O ovo cai dentro do recinto do animal e Frank o recupera, comendo-o sujo como estava, mesmo sobre a contrariedade de Shane.

"Se consumir antes de 10 segundos não tem problemas" é a frase dita por Frank após a ingestão do ovo, quando alertado por Shane sobre a sujeira presente neste.

A partir deste ponto inicia-se a narrativa da segunda história, quando por meio de animação, tem-se a representação do que ocorre dentro do corpo de Frank. E o que se vê é que, além da sujeira presente no ovo ele é invadido por um vírus, “A Morte Roxa”, cuja ação no corpo de Frank inicialmente provoca sintomas semelhantes aos de uma gripe simples.

\footnotetext{
3“'É um termo usado para designar filmes, seriados e afins, com atores reais, em oposição às animações, cujos personagens são em desenho, e não atores de carne e osso." Disponível em http://www.tvsinopse.kinghost.net/ou/dicionario.htm. $\quad$ Acesso $\quad$ em: $\quad 02 \quad$ fev. 2016.
} 
Assim inicia-se a viagem pela "Cidade de Frank", na qual o público é apresentado a vários personagens, entre eles, Osmose Jones, representando um leucócito, célula branca do sangue, jovem policial que anseia por aventuras maiores do que apenas capturar germes que invadem a boca. Osmose nos leva a uma caçada pelo vírus invasor em companhia de Drix, a pílula que Frank ingere, sem orientação médica, para tentar aliviar os sintomas que sente decorrentes da ação do vírus.

\section{Figura 5 - "A cidade de Frank" (representação em animação do corpo de Frank)}

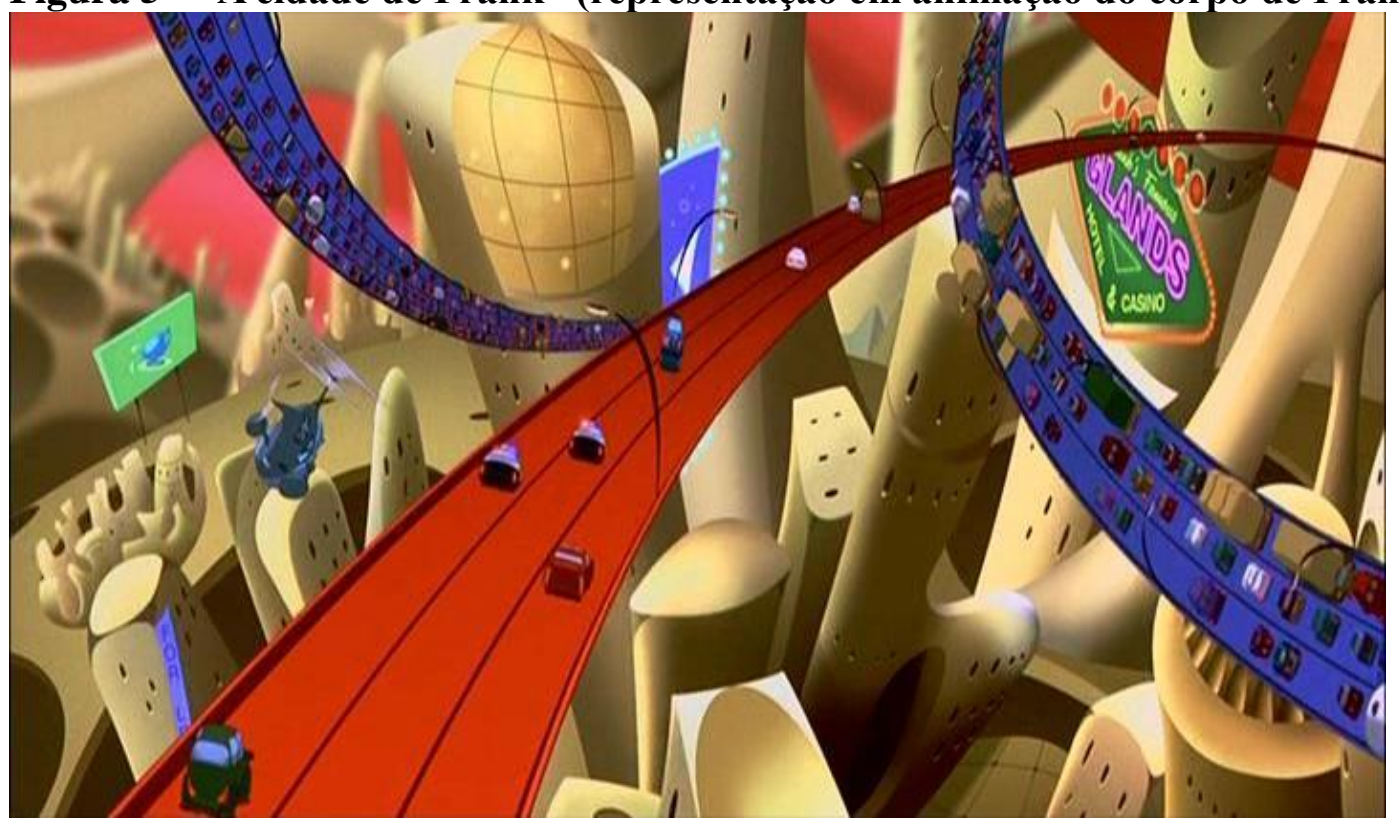

Fonte: Imagem disponível em https://afureko.files.wordpress.com/2013/03/osmosis-city.jpg

Figura 6 - Personagens do Filme: Osmose Jones e Drix

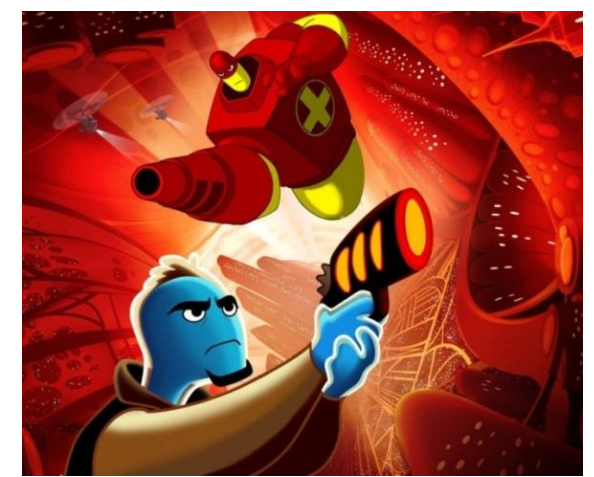

Fonte: Imagem disponível em https://ricalexhq.files.wordpress.com/2015/10/oj_-4.jpg

Assim, após assistir o filme, de forma completa, algumas cenas específicas foram revisadas individualmente, cruzando-se o que era retratado nestas com o que se pede sobre o ensino do funcionamento do corpo humano nos PCNs de Ensino de Ciências Naturais (BRASIL, 1998).

Estas cenas trazem determinadas analogias que permitem ao aluno compreender, de forma bem didática, a função e a importância de alguns órgãos e estruturas do corpo humano, tais como os componentes do sistema circulatório e do sistema nervoso, afinal, cada porção 
dentro do corpo de Frank é representada como uma parte de uma cidade que possui um prefeito, delegacia, bairros mais pobres e mais ricos, vias de trânsito, cinema, boates, aeroporto, foras da lei, entre outras coisas, conceitos com os quais os alunos estão mais acostumados a lidar e que facilita a transposição para entender o funcionamento do organismo humano.

Alguns aspectos do funcionamento deste organismo, inclusive, são bem retratados, como as cenas que mostram especificamente o início do processo de digestão no personagem Frank; as imagens da evolução de um processo de infecção; os mecanismos de defesa corporal na região do nariz, culminando com um espirro; além de cenas que retratam a coordenação nervosa do corpo, incluindo os sonhos e o funcionamento do subconsciente.

As questões propostas na Atividade 1 do Guia fazem referência justamente a estas cenas, de forma a verificar se os alunos serão capazes de fazer a transposição do que é retratado no filme para o funcionamento real do corpo.

Outro aspecto que foi analisado em algumas cenas do filme são os efeitos danosos ao organismo causados por algumas situações vivenciadas por Frank, os quais servem de alerta para trabalhar determinados cuidados que se deve ter na busca por manter o organismo saudável. Tal análise foi usada na construção da Atividade 2.

Por último, a atitude que Frank tem de ingerir um medicamento sem prévia consulta a um profissional especializado possibilita abordar questões importantes com os alunos e, uma delas seria o risco da automedicação, tema abordado na construção da Atividade 3.

O professor pode aproveitar também para fazer com que os alunos pensem na questão de como sofremos com a mídia no que se refere a imposição de determinados padrões, não apenas estéticos, mas também no consumo de alimentos.

Assim é possível com o uso das atividades 2 e 3, que o professor extrapole um pouco do que é pedido no que se refere aos conteúdos conceituais nos PCNs de Ciências, trabalhando aspectos pontuais relacionados a saúde, que são pedidos nas sugestões dos temas transversais.

Pretende-se desta forma que as sugestões de atividades propostas neste guia possam servir como mais uma ferramenta pedagógica na prática docente.

\subsection{PÚBLICO ALVO}

As atividades sugeridas no guia foram pensadas inicialmente para os alunos do ensino fundamental, mas nada impede que sejam aplicadas a alunos do ensino médio, cabendo ao professor fazer uma adequação de linguagem e nível de conteúdo, uma vez que o tema "Ser Humano e Saúde" faz parte também do currículo deste nível de ensino.

É necessário que o professor tenha um conhecimento de seus alunos para saber o melhor momento de fazer uso desses recursos, garantindo que estes sejam realmente complementos de sua prática pedagógica e que o ato de exibir um filme para os alunos não seja apenas uma atividade para ocupar um espaço de tempo, sem objetivo algum.

\section{2 ATIVIDADES DO GUIA EDUCATIVO}


Seguem as propostas de atividades. Vale lembrar que o professor deve estar atento às necessidades de seus alunos e à realidade de seu ambiente escolar, fazendo as adaptações que considerar adequadas e necessárias.

\section{Atividade 1: Viajando pelos sistemas}

Esta atividade tem por objetivo rever e fixar o conteúdo referente ao funcionamento dos sistemas. O professor deverá exibir o filme após trabalhar os conteúdos necessários. A atividade consiste em um roteiro de perguntas específicas e em uma pesquisa sobre a função e importância do sistema imunológico, introduzindo o tema Vacinas.

Figura 7: Sala da prefeitura da "Cidade de Frank", que permite estabelecer uma comparação com a função do Sistema Nervoso Central em nosso organismo

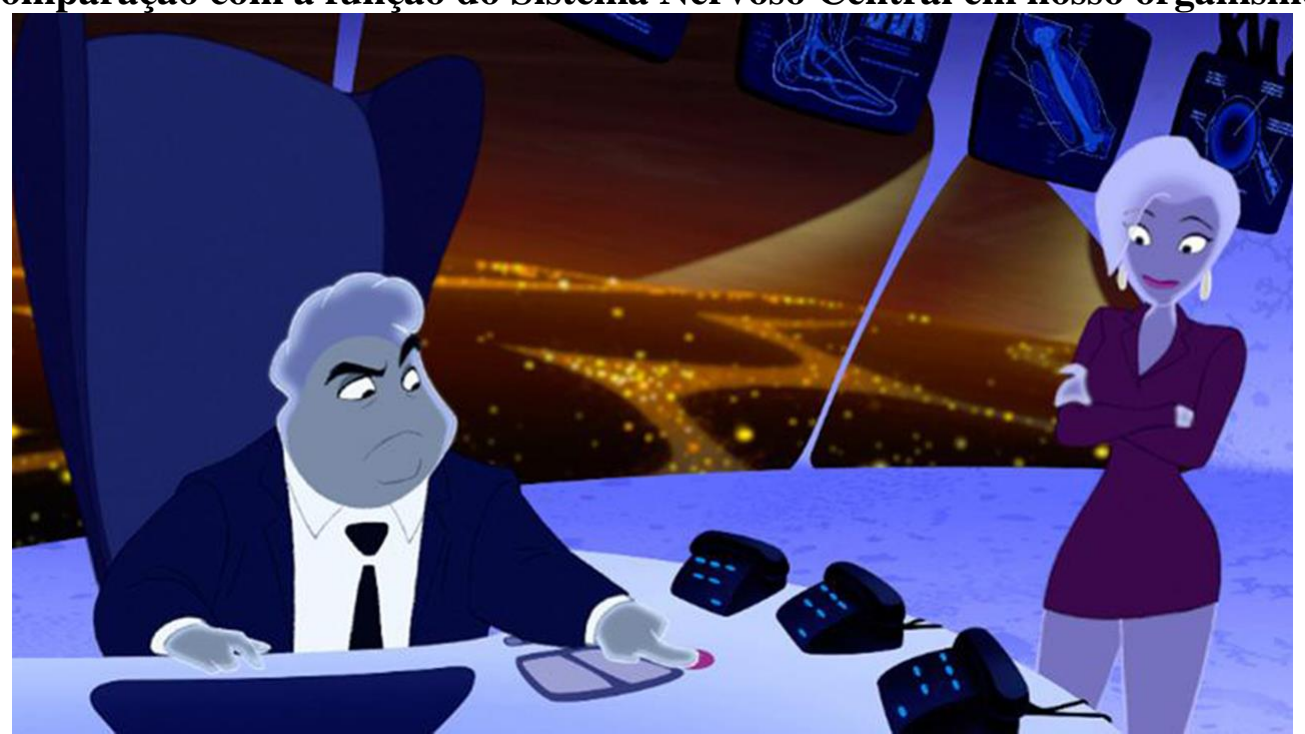

Fonte: Imagem disponível em http://image.tmdb.org/t/p/w1560/wiaByoT3R75rVQSQaDq4iQDQxHY.jpg

O filme Osmose Jones permite uma viagem por dentro do organismo de Frank. Vamos agora rever alguns temas que estudamos por meio do que o filme nos mostrou:

1) Osmose Jones é o personagem principal da animação e representa um elemento figurado do nosso sistema circulatório sanguíneo:

a) que elemento seria esse? Qual a função que ele desempenha em nosso organismo?

b) quais outros elementos figurados existem no sangue? Quais as funções destes?

c) os vasos sanguíneos são representados no filme por ruas e avenidas, inclusive com congestionamentos. Em nosso organismo o que poderia levar a um "congestionamento" de nossos vasos?

d) considerando estes mesmos vasos sanguíneos, porque alguns estão representados com cor azul e outros com cor vermelha no filme?

e) apesar de não ter sido mostrado diretamente no filme, para se ter o fluxo de sangue em nosso organismo, contamos com o papel especial de um órgão. Que

ISSN 1982-4866. Revista Dynamis. FURB, Blumenau, v. 22, n. 2, p. 35-51, 2016 
órgão seria este? Faça um esquema deste relacionando a circulação pulmonar e a circulação sistêmica.

2) No filme, a "Cidade de Frank" é governada pelo prefeito Sr. Phlegmming, também uma célula sanguínea, que não quer abrir mão do poder, mas que não vem realizando bem a sua função. Seu local de trabalho é a sala de controle de onde tem acesso a todas as funções do corpo de Frank:

a) a sala de controle usada pelo prefeito faz referência a qual sistema existente em nosso organismo?

b) para que servem os nervos (representados no filme como cabos elétricos que percorrem o corpo de Frank)?

3) Drix, fiel parceiro de Osmose na aventura, em determinado momento no filme é informado que seu tempo no organismo de Frank se encerrou e que ele deve ir embora. Em nosso organismo acontece a mesma coisa com os medicamentos que ingerimos: após a ação destes o que resta deve ser eliminado.

a) qual sistema do nosso organismo é responsável pela eliminação dos restos de medicamentos após a sua ação no organismo?

b) as substâncias tóxicas são retiradas do organismo através da filtragem do sangue. Quais órgãos realizam este processo?

c) após o processo de filtragem sobre a forma de qual líquido as substâncias tóxicas serão eliminadas do nosso organismo?

4) Uma das cenas do filme mostra o intestino como um lugar totalmente poluído na cidade de Frank. Assim como no início do filme, temos a visão da boca de Frank com uma série de problemas de higiene (cáries nos dentes, gengivite e tártaro).

a) estes dois órgãos, boca e intestino, integram qual sistema de nosso organismo?

b) podemos resumir as funções deste sistema em três funções básicas. Quais seriam estas?

c) quais outros órgãos são integrantes deste sistema? Faça um apontamento do que acontece em cada um deles.

5) Um sistema pouco mostrado no filme é o Respiratório, do qual nossos pulmões fazem parte. O que acontece nestes órgãos?

6) Em uma cena, Frank nos mostra um processo de defesa do organismo, o espirro. Tal reação está ligada ao nosso sistema Imunológico.

a) pesquise sobre este sistema procurando entender como ele atua no nosso organismo.

b) o que seriam anticorpos e antígenos?

c) o que são as vacinas? Qual a importância destas? 


\section{Atividade 2: O risco da automedicação}

Esta atividade tem como objetivo promover um trabalho de conscientização e prevenção sobre os riscos da automedicação.

Figura 8 - A filha de Frank observa a garganta do pai e recomenda chamarem um médico, mas Frank diz que tomaria um comprimido para aliviar o mal estar

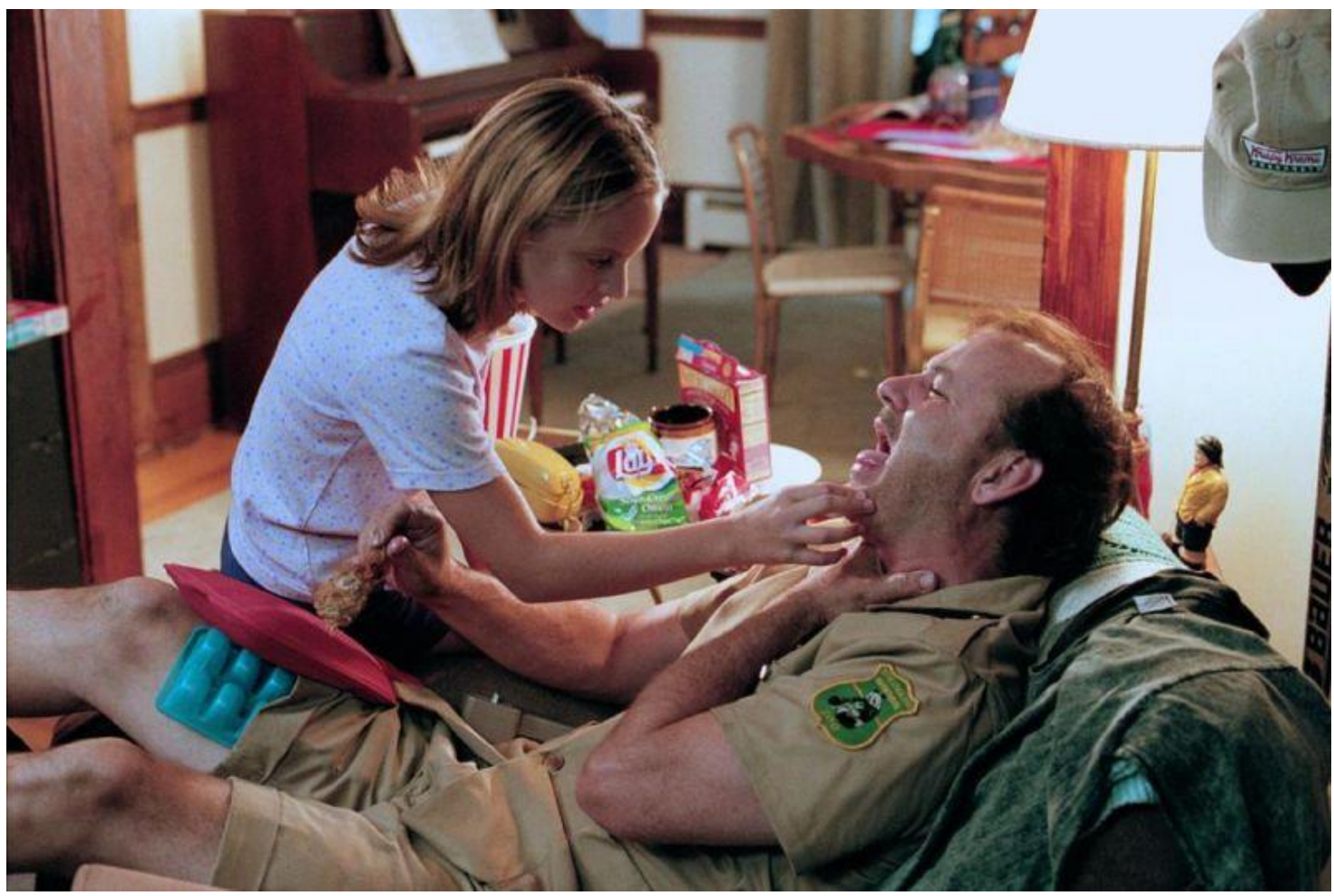

Fonte: Imagem disponível em http://images3.cinema.de/imedia

Depois dos alunos assistirem o filme, deve ser promovida uma discussão a respeito do tema em questão.

As perguntas a seguir podem ser usadas para estimular a discussão:

- Você acha que a postura de Frank foi correta em usar um medicamento sem orientação médica?

- Na sua casa existe o costume de tomar medicamentos sem a orientação de um médico? Se sim, quais medicamentos são tomados? Por quê? Quem os indicou?

- Você acha que os chás medicinais podem trazer algum risco para nossa saúde se tomados sem orientação?

No site da Agência Nacional de Vigilância Sanitária - ANVISA (http://portal.anvisa.gov.br/wps/portal/anvisa/home) na guia "Educação e Pesquisa", e depois em "Campanhas" estão disponibilizados materiais da campanha "A informação é o melhor remédio". Estes materiais incluem vídeos, cartazes, áudios e material de apoio ao profissional, no qual são sugeridas algumas atividades. 
Dentre estas atividades, é pertinente destacar a de número 5, que diz respeito a fazer uma pesquisa na comunidade escolar sobre os hábitos de automedicação.

Os alunos devem elaborar perguntas com o auxílio do professor. Posteriormente, as perguntas devem ser organizadas em forma de questionário que será aplicado a todos os membros da comunidade escolar (professores, pais, funcionários e alunos de outras turmas). O resultado, após tabulação das respostas, deve ser apresentado, então, na forma de cartazes.

A atividade proposta é interessante pois possibilita uma visão maior a respeito dos hábitos das pessoas com as quais os alunos convivem diariamente. No entanto, é importante que o professor faça um segundo momento de discussão com os alunos acerca dos resultados obtidos, e que junto à divulgação sejam colocados cartazes de alerta sobre o risco da automedicação.

Uma complementação desta atividade pode ser feita também por meio de pesquisas sobre os riscos que o uso dos medicamentos mais usados sem orientação médica trazem as pessoas.

\section{Atividade 3: Cuidados com o Corpo}

Esta atividade tem por objetivo conscientizar os alunos de que manter o corpo saudável envolve uma série de hábitos relacionados à higiene, alimentação, prática de atividades físicas, ambiente tranquilo, entre outros fatores sociais.

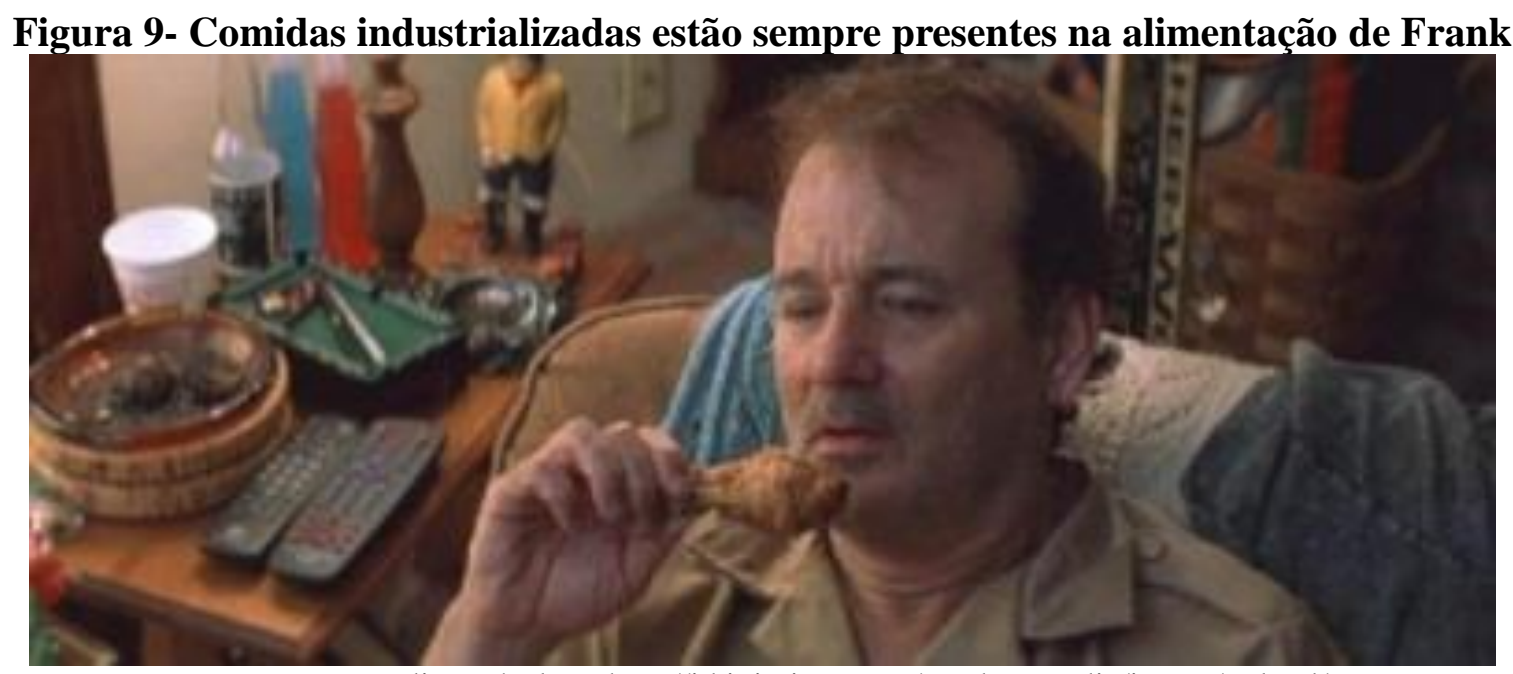

Fonte: Imagem disponível em http://i.kinja-img.com/gawker-media/image/upload/s

Num primeiro momento, o professor, após a exibição do filme, discutirá com seus alunos quais situações mostram o descuido de Frank com sua saúde. O professor deve estar atento se os alunos mencionarão situações relacionadas à alimentação e a prática de atividades físicas. Ele deve também inserir na discussão apontamentos sobre como o ambiente em que vivemos pode afetar nossa saúde.

No segundo momento a turma deve ser dividida em grupos e cada grupo será responsável por apresentar aos demais alunos doenças como hipertensão arterial, diabetes, obesidade, bulimia, entre outras que o professor considerar pertinentes. 
Os alunos devem abordar os sintomas destas doenças, suas possíveis causas e como as pessoas devem agir para se prevenir e tratar.

Para que a atividade seja mais dinâmica, os alunos podem organizar teatros em que situações relacionadas às doenças sejam dramatizadas.

Uma complementação desta atividade, mais dinâmica, é que o professor(a) de Ciências junto ao professor (a) de Educação Física e outros profissionais da escola promovam uma gincana de jogos e brincadeiras aliados à alimentação saudável. Os alunos serão escalados para competir entre si em diversas modalidades (futebol, vôlei, peteca, queimada, cabo de guerra, dança das cadeiras, brincadeiras com balões e outros conforme o espaço e tempo disponíveis). Sugere-se que sejam fornecidas frutas na merenda ou que os alunos sejam estimulados a trazê-las de casa. Pode ser organizada uma salada de frutas por turma.

\section{CONSIDERAÇÕES FINAIS}

A realização deste trabalho permitiu observar que mesmo vivendo em uma época em que existem ferramentas tecnológicas complexas disponíveis para o ensino, nem todas as escolas têm condições de dispor das mesmas.

Isso não quer dizer que o professor não possa tornar suas aulas mais atrativas: alguns materiais, inclusive, alguns de fácil acesso, estão à disposição no cotidiano e são atrativos para os alunos, como é o caso dos filmes de animação, lançados no mercado. Se usados com uma orientação específica eles acabam por tornar o estudo de determinados conteúdos algo mais próximo e com sentido para os alunos.

É necessário lembrar que selecionar um material adequado e pensar em como utilizá-lo, de forma que este atinja o objetivo desejado é uma tarefa que requer tempo e atenção.

E este relato traz justamente um produto pensado nestes moldes, que possibilitará ao professor trabalhar junto aos alunos o funcionamento do Corpo Humano, extrapolando para as questões de cuidado com este corpo.

Espera-se que o Guia do Educador para o Filme Osmose Jones seja de grande valia para você educador.

\section{REFERÊNCIAS}

BRASIL. Parâmetros Curriculares Nacionais (PCNs). Terceiro e quarto ciclos do ensino fundamental - Ciências Naturais. Brasília: MEC/SEF, 1998.

CABALLER, M.J. e GIMÉNEZ, I. Lasideas de losalumnos y alumnas acerca de laestructura celular de los seres vivos. Enseñanza de lasciencias: revista de investigación y experiencias didácticas. v.10, n.2, p.172-180, 1992.

CASTOLDI, R.; POLINARSKI, C. A.. A Utilização de Recursos Didático-Pedagógicos na Motivação da Aprendizagem. I SIMPÓSIO NACIONAL DE ENSINO DE CIÊNCIA E TECNOLOGIA. 2009. Disponível em <http://pt.scribd.com/doc/45106081/A-Utilizacao-deRecursos-Didatico-Pedagogicos-na>Acesso em: 20 abr. 2016. 
FERRACIOLI, L. Aprendizagem conhecimento e desenvolvimento na obra de Jean Piaget: uma análise do processo de ensino aprendizagem em Ciências. Revista Brasileira de Estudos Pedagógicos. Brasília, v. 80, n. 194, p. 5 -18, jan/abr.1999.

MOREIRA, M. A.. A Teoria da Aprendizagem Significativa de Ausubel. In: MOREIRA, M. A.(Org.). Teorias da Aprendizagem. São Paulo: Editora Pedagógica e Universitária, 1999. p. 151-165.

SILVA, I.M., et al.. Automedicação na adolescência: um desafio para a educação em saúde. Ciência e Saúde Coletiva, v. 1, p.1651-1660, 2011.

SILVA, M.A.S., et al. Utilização de Recursos Didáticos no processo de ensino e aprendizagem de Ciências Naturais em turmas de $8^{\circ}$ e $9^{\circ}$ anos de uma Escola Pública de Teresina no Piauí. In: VII CONGRESSO NORTE NORDESTE DE PESQUISA E INOVAÇÃO. Palmas, TO, 2012. Disponível em http://propi.ifto.edu.br/ocs/index.php/connepi/vii/paper/viewFile/3849/2734>. Acesso em 20 set. 2016.

SOUZA, S. E. O uso de recursos didáticos no ensino escolar. In: I ENCONTRO DE PESQUISA EM EDUCAÇAO, IV JORNADA DE PRÁTICA DE ENSINO, XIII SEMANA DE PEDAGOGIA DA UEM: "INFANCIA E PRATICAS EDUCATIVAS". Maringá, PR, 2007. Disponível em: <http://www.pec.uem.br/pec_uem/revistas/arqmudi/volume_11/ suplemento_02/artigos/019.pdf >. Acesso em 17 nov. 2013.

VEEN, W; VRAKKING, B. Homo zappiens: educando na era digital. Porto Alegre: Artmed, 2009.

\section{REFERÊNCIA DO FILME}

OSMOSIS Jones (título original). Direção: Bobby Farelly e Peter Farelly. Estados Unidos: Warner Home Video, 2001, 1 DVD, 95min. 